\title{
The Implementation of Adopted Balanced Scorecard with New Insight Strategy Framework for the Healthcare Industry: A Case Study
}

\author{
Kim-Fatt Khiew1, Mingchih Chen', Ben-Chang Shia' ${ }^{2}$, Chun-Hen Pan ${ }^{3}$ \\ ${ }^{1}$ Graduate School of Business Administration, Fu Jen Catholic University, Taiwan \\ ${ }^{2}$ School of Health Care Administration, Taipei Medical University, Taiwan \\ ${ }^{3}$ Alison Maternal and Child Clinic, Taiwan \\ Email: jimmykhiew@gmail.com,081438@mail.fju.edu.tw, stat1001@tmu.edu.tw,eve770510@gmail.com
}

How to cite this paper: Khiew, K.-F., Chen, M., Shia, B.-C. and Pan, C.-H. (2020) The Implementation of Adopted Balanced Scorecard with New Insight Strategy Framework for the Healthcare Industry: A Case Study. Open Journal of Business and Management, 8, 600-627.

https://doi.org/10.4236/ojbm.2020.82036

Received: December 25, 2019

Accepted: March 1, 2020

Published: March 4, 2020

Copyright $\odot 2020$ by author(s) and Scientific Research Publishing Inc. This work is licensed under the Creative Commons Attribution International License (CC BY 4.0).

http://creativecommons.org/licenses/by/4.0/

(c) $\underset{\mathrm{By}}{\text { (i) Open Access }}$

\begin{abstract}
Purpose: The purpose of this paper is to find out the new insight and concept of management strategy for Taiwan local clinic in a low reimbursement insurance payment system. Besides the golden spirit of keeping human healthy and best quality of life style, creating stable financial income is another big issue. However, healthcare industry is highly competitive among same industry as well as high-end technology investment. Therefore, a suitable dynamic strategy should be taken into consideration further healthcare service undertaking. After the implementation of adopted balanced scorecard with new in-sight strategy toward child and maternal clinic, and additional of SWOT analysis, Blue Ocean Strategy and 7s Mckinsey theory, a suitable dynamic strategy created a great value in health care industry. It created a value added dynamic strategy to solve low reimbursement insurance payment system; local clinic not only gained a better profit and service expansion but also promoted health care to a higher level, especially in child and maternal healthcare services. Design/Methodology/Approach: This is a local Obs \& Gyn local clinic qualitative case study. All observation phenomena were observed and recorded down from the clinic. Adoption of balanced scorecard, new insight of blue ocean strategy and 7's Mckinsey Theory formulates a dynamic strategy for the clinic management.
\end{abstract}

\section{Keywords}

Adopted Balanced Score Card, Blue Ocean Strategy, 7s Mckinsey, Dynamic Strategy, Healthcare Industry, P Obs \& Gyn Clinic, A Obs \& Gyn Clinic, Value-Added, Innovation 


\section{Introduction}

This is a case study of a maternal and child healthcare clinic in Taiwan. How and why a local Taiwan maternal and child healthcare clinic develops the implementation of adopted balanced scorecard with new insight strategy framework for the healthcare industry? Furthermore, how to formulate the dynamic strategy for better management, better profit margin and best quality of medical service to the maternal and child? These two questions will be answered in this paper.

To date, the competition among players within the health-service industry in Taiwan has become complex [1]. The implementation of National Health Insurance program is identified as the dynamic factor that must be dealt wisely by the player. Study done by Brody [2] concluded that the citizen awareness regarding the good healthcare has doubled for the past two decades, including in Taiwan. More citizens view good health care service as one of the responsibilities from the nation to protect their generations. These factors make baby care centers as one of the subjects upon national agenda. In 1989, the women of Taiwan had their first kid when they were 25.2 years of age. But in 2013, this number has been deferred to 30.4 years of age [3]. This showed that the trends of marriage and having a descendant would become a major issue for the next 20 years.

Since the introduction of the Balanced Score Card in MacKay Memorial Hospital in early 2000 [4], many health-care players have tried to adapt this new concept into their practice. Though the concept is not well-prepared for the service industry [5] [6] [7], there have been at least 39 published manuscripts between 2000 and 2015, which focus on how the balanced score card should be implemented in Taiwan, ranging from the big capacity of hospital to local clinic. Drawing back to several manuscripts [8] [9], the concept can be well implemented even in small organizations. One consideration is that in most cases, failure in implementing the concept is caused by the lack of readiness in the organization to adapt the new paradigm. This may include: 1) structured fitness between what is desired by the concept and the dreams of the shareholder, 2) the values underlying the whole organizational framework-for most cases, non-profit organizations still struggle with the sustainability concept while the BSC poses strictly this thought, 3 ) the bureaucratic procedures-since the BSC requires a systematic procedure that binds the overall performance.

To answer how and why a child and maternal healthcare needs a new insight to adopted balanced scorecard, the reasons are clearly stated of low reimbursement of payment from National Government Insurance System. Extra charges from patient is prohibited unless those items are not in the insurance list. Therefore, creating baby health care services, postpartum confinement center, early childhood education and overseas regional geographic consultancy are profitable income instead of restricted insurance payments system. However problems are financial support, land and building properties as well as skillful staffs' collaboration.

Putting all considerations together, this study will investigate the optimal path 
to adopting the concept using a Local Clinic for maternity and child care center in Taiwan. Through detailed and proper observations, the study tries to provide 1) a clear insight regarding how to address the concept into a real business challenge, 2) strong framework based on combined theoretical and managerial consideration in adopting the BSC. Before A clinic, the owner has his P Obs \& Gyn clinic in the same district which was established in 1980, P clinic was the pioneer for Obs \& Gyn medical services in this district. P clinic was an ordinary obs \& gyn clinic with 3 storeys house building, running by one doctor (the owner) and 24 nursing staff, mainly practice in obstetric disease treatment and birth delivery. In 2005, the shareholders decided to establish a high quality of maternal and child healthcare center-A Obs \& Gyn clinic with a larger scale of space. This included physical-building designs and renovations to provide a one-stop health care service for women and improvement in the medical instrument quality and management system.

Competition in the same industry as well as high-end technology has led to a tumultuous atmosphere in the healthcare system. In addition, prolonged working hours, staffing shortages, abuse of medical expenses, and low reimbursement rates have also helped instigate a red ocean crisis in the healthcare industry. The strong health-seeking behavior in the Taiwanese culture drives many individuals to seek consultations from famous doctors as well as visit large medical centers with night medical services. As a result, there is a decrease in patients attending local clinics.

\section{Literature Review}

\subsection{SWOT Analysis}

The background and history of SWOT-strengths, weaknesses, opportunities, and threats-was first proposed by Albert Humphrey in the early 1960s-1970s. The medical services-hospitals and clinics-in Taiwan face high competition, incur significant investments in high level technology and equipment, and also have low reimbursement rates. These are all challenges that the A Clinic confronts currently. This will allow A Clinic to develop successful strategies to tackle weaknesses and threats to the organize [10], as well as combat other challenges posed by the Taiwanese healthcare industry.

The main strength of A Clinic is the internal factors of human resources, as it is a five-star hospitalized accommodation, professional pediatric and obstetric specialists' expertise, experienced administrative staff and well medical service training programs. Additionally, it is also affiliated with a nursing school. A strong staff allows the clinic to provide effective medical care, focuses on optimizing patient-provider relationships, while allowing the practice to establish its own public reputation [11].

In terms of its weaknesses, to be successful, A Clinic must confront the current red ocean of the healthcare industry. Some challenges the practice faces include a lack of famous doctors, shortage of nursing staffs, high rental payment 
and maintenance fees, as well as investments in advanced technology and medical equipment that will bear significant financial risk [12]. A lack of physical resources-patient rooms, staff rooms, conference halls, auditoriums, and teaching facilities-are additional factors that undermine its success [11]. In order to improve the lean healthcare service, the healthcare industry must adopt an electronic, computerized medical record system that is integrated with all medical investigation results [13].

A Clinic also encompasses an abundance of opportunities that can be further developed to optimize and propel the success of the organization. For example, the practice is well established on the Internet and social media by utilizing Line groups with different parties to streamline communication. QR codes containing all relevant information about its services are also available. A Clinic has also established the Chinese Women and Children Development Association to promote free health education to the community and also provides professional training program in newborn and early childhood care and education with a certification process [11]. The threats that A Clinic faces, business model obstacles, new entrants posing as competition, reduction in local population and thus demand, increase in salary expenses, potential for future growth, negative reviews on the Internet, as well as low reimbursement rates from the National Health Insurance Policy. Therefore, A Clinic needs to conduct a SWOT analysis to formulate a successful strategy [14] to combat all possible threats currently and in the future.

\subsection{Innovation and the Blue Ocean Strategy}

Conceptualized by Kim and Mauborgne [15], the concept directed us to create an uncontested market space, which makes the competition irrelevant. Furthermore, Kim and Mauborgne expressed more detail of Blue Ocean Strategy with four action frameworks, that is Raise, Create, Reduce, and Eliminate to draw a new value curve. Kim and Mauborgne [15], they mentioned the key rule in generating a new operation model, the strategic team should know "Cost saving are made by eliminating and reducing the factors an industry competes on" and "Buyer value is lifted by raising and creating elements the industry has never offered".

Referring to Kim and Mauborgne [15], a red ocean strategy implies that a company must develop competitiveness, which will one day be used to diminish another competitor in order to control the monopoly power within the battle. But as a physician theory mentioned that 'one will react if anyone posed the action' therefore the red ocean will only result in zero sum games [16] [17] [18]. The basic requirement from the blue ocean strategy is an innovation, including product and service innovation. Yang and Yang [19] explained that the basics of blue ocean innovation are found in a value creation model. A medical doctor and Genuine hospitality will help increase higher patient satisfaction. This can trigger a long-lasting patient-provider relationship based on loyalty and com- 
mitment. Parvinen et al. [20] argued that performing an uncontestable market relates to marketing strategy to open a new market inhabited by any other player. The majority of the end process in managerial techniques will be on marketing efforts [21] [22] [23]. The core competence can be derived from the first entrants. Von Krogh [24] mentioned that for competition that is characterized by faster growth in the industry, only those who lead the market would benefit more. Others only serve the niche market that the leader has failed to serve. If a company is still willing to serve this segment, then it most likely will need to cut down the expected margin [25].

One new trend in the global medical industry is the belief that the value of the blue ocean spirit is in its emphasis on relationships can turn the supplier into becoming one of our informants. Having done so, the company will be able to identify any sudden actions from its competitors [26]. Once the company succeeds in occupying one market, then the other company will follow. As a result, the blue ocean is always followed by another red ocean [27] to retrieve the customers. Demands are not created but drawn from other markets. Thus, in practical terms, to provide a blue ocean, one must engage in the red ocean [28]. On the other hand, the concept is also highly recognized due to its simplicity. Combined with strong supports from technology, the company has the ability to use the concept to redefine market opportunities using innovation [29].

One of the core elements in the blue ocean strategy is innovation [15] to motivate business organizations to find new approaches to achieve higher productivity to elevate effectivity and efficiency [30]. Close relationships may guarantee the quality of the product supplied to the company and also the appropriate quantity of supply. This type of relationship also leads the two players to exchange valuable information between one another [31] [32] but protecting the current player within competition is necessary as a means for a barrier against new entrants. New entrants introduce a new fear since they always conquer the market with new abilities and more innovative technology [33], or even abundant source of capital [34].

Innovation at the edge of the blue ocean strategy can be seen from an industrial perspective. As Lindic et al. [35] mentioned, once the local industry succeeds in implementing the blue ocean strategy through a proper innovation process, then there should be positive impact on the national economic policy and performance. Robertson and Langlois [36], who tried to relate innovation with networks and vertical integration also support this idea. In this paper, the author explores the firm mechanism to adopt the new concept of innovation internal capability and external network is used to provide new knowledge to create new innovation ideas that may be beneficial. The integration between strategic business sometimes is necessary to perform the hidden capability in creating new innovation [37] [38]. Compared to horizontal integration, vertical integration prefers less complexity in terms of confidentiality [39]. As Lieberman and Montgomery [40] explained, becoming the first mover in the industry 
creates opportunities for the player to set up the core mechanism for future competition and also they become easily reminded by the community. This is the basis for loyalty [41] provides an opportunity for stable profit over a longer term.

\subsection{The 7S McKinsey Theory}

Featured in the book In Search of Excellence, by former McKinsey consultants Thomas J. Peters and Robert H. Waterman, the model draws a constellation of interrelated factors that influence an organization's ability to change. The framework are: 1) to facilitate organizational changes, 2) to help implement a new strategy, 3) to identify how each area may change in the future, and 4) to facilitate the merger of organizations.

Singh [42] explained why organization needs these tools to perform innovation. The soft elements consist of 1) shared values, 2) style, 3) staff and 4) skills. The shared values refer to the organization's vision and mission. Bass and Avolio [43] mentioned that the first four elements are the true representation of the organization's direction. The second set is composed of hard elements. This category consists of 1) strategy, 2) structure and 3) systems. Once the organization has developed the first four elements properly, it will have the ability to create a more comprehensive strategy, a better structure, and an effective system to guarantee any future performance. The second consideration is related to how the first four can be a foundation for the other elements. In order to solve the problem while creating innovation, an organization needs to strengthen their cultures by extrapolating company needs into each individual's objective, thus creating mutual cooperation among all members.

\subsection{The Balanced Score Card}

Proposed by Kaplan and Norton in early 1990's, the Balanced Score Card is a useful tool to portray, analyze and develop a strategy. The concept of balanced scorecard had been rejuvenated many times due to critics from field practices [44]. Some organizations tend to use the term innovation (product and service innovation) to provide a better way for productivity. Among those who succeed in performing this mechanism, several have used knowledge management systems to provide new insights for the terms [7].

Once the organization succeeds in serving the customer better, they will change their position from a regular customer to a loyal customer. Implementing the balanced scorecard in the medical field is also faced with constraints, especially when one needs to address productivity. A doctor has to treat their patients within rush hours. Saving lives would mean providing accurate diagnoses [45], in a short amount of time [46] and with the use of affordable resources [47]. Therefore, there is a need to identify the best strategy to bring the quality in health service sector into a more patient-centered approach [48].

One proposed alternative using the balanced scorecard for a health care sector was proposed by Grigoroudis et al. [49]. A non-profit organization willing to 
engage with the BSC needs to consider using accurate performance measurement tools such as key performance indicators. A financial perspective must be based on a series of financial-related logics and this basis can become another new insight for the organization to develop their knowledge management capabilities [50]. Health medical services are now identified not only in terms of giving treatment, but also as providing the appropriate psychological environment to the treatment to be friendly with their environment and the surrounding neighborhood. By maintaining a positive spirit, they are able to earn positive responses from the society [51]. From a strategic management perspective, every business policy which denotes the financial perspective, internal business process and customer should reflect the true shared-value of the overall organization [52] [53] [54] [55].

In our perspective, the vision-mission and objective of the organization should be positioned as the central point when we want to develop the card that represents the desired core values of the founding father [56]. The statement provides a clear direction to the entire organization, including the selection of the most appropriate measurement tools to develop the strategy. A hospital surrounded by a high social class society will have a good prospect for future revenue. If the hospital were established in middle-low social class society, then it would be harder to run the medical services. Without prior justification to the observed concept, the only option that we have now is positioning the internal business process as the key element in the balanced scorecard [57].

Improving the ability of the organization is not simple. The organization must be able to provide a clear strategy to boost their knowledgeable workers. This can be performed through a formal education and a non-formal education process [58]. Newhouse [59] mentioned that the most comprehensive way to boost the performance of all members within the hospital management team is by having an integrated education process. Senior members can transfer all existing knowledge and experience to junior staff. By letting the staff have similar experiences in the daily medical operation, it is believed that they will learn from their mistakes [60].

\section{Research Methods}

This study uses a qualitative case study approach. According to Yin [61], the case study is the best approach that captures every detail in observation object. The case study has been widely used for many years and has been proven to be the best approach to draw a theory from [62]. In the medical field, a case study has proven to be of benefit to the knowledge development process since it can be used in the basic consideration for specific decisions [63]. For the learning organization, developing a theory from a case study is very important. Today, many players within the medical sector use the case study as a method to deal with new disease.

The case study research begins with a unit of analysis. This is the observed 
phenomenon in which the researcher is trying to analyze. Conceptually, the unit of analysis can be a human being or an organization. Though they are somewhat different, humans and organizations are similar in terms of life cycle. Both of them must be seen as living cells that have gone through specific levels of maturity. The dynamic factor of the unit of analysis is the phenomenon that can be observed by many researchers who use different perspectives. This study tries to analyze the use of the balanced score card by an organization. The concept of the balanced score card is actually a fixed term, unless the author continues to develop the theory. But the way an organization tries to adopt the concept is what makes the balanced scorecard alive. Every constraint and challenge found in the practical field is justified as new insight to the concept. Therefore, researchers need to identify every part to stay in focus with the study's objective.

The second point that should be considered in using a case study is related to problem identification stage. For some scholars, maintaining flexibility in the case study approach is necessary as what they originally think can actually be different from what they have experienced practically. Researcher may draw the list of questions from a comprehensive literature review done on the previous section. Former questions used by some published manuscript can also be of guidance for the study. Once the field interview is completed, researchers must evaluate whether their original question is still relevant with the observed object. According to Pentland [64], aiming to develop a new insight or a theory, researchers must know that they are dealing with a living object-including an organization. Mixture of cultures among respondents is one way to make the case study method become more relevant compared to other approaches. A researcher needs to acknowledge the maturity of each informant in answering their question. Different education levels, cultural backgrounds, ethnicities and even religions may share a different finding. This is why, once they have identified the direction of the study that needs to be changed according to the collected information, researchers need to revise their original research question.

For some reasons, a case study approach seems to lack structured steps. Plummer [65] posited the importance of a researcher in preparing a structured method in using case study as a research method. These steps include: 1) selecting the most appropriate unit of analysis, 2) performing a preliminary study on the observed unit of analysis, 3) developing a research question, 4) preparing a list of questionnaire protocols, 5) selecting the potential candidate for informant and 6) choosing the most appropriate data-collection technique. Although the steps are structurally proposed, some researchers still find the possibility to change the order of the previously stated steps in a practical field. This is why we can mention the importance of maintaining flexibility. The last point to be considered in using a case study approach is regarding the needs to use a single or multi case analysis. Relating to Stake [66], the choosing process actually depends on the objective of the study. We decided to use a single case analysis but will still accommodate new insights from an industrial perspective. We deployed a 
structured focus group discussion among experts to have their insights regarding several points: 1) the future growth of the industry, 2) demands of the future market, 3) potential barriers for the industry, 4) the best practice within industry and 5) managerial tools that can accommodate the eagerness of Taiwan to be the best player in medical sector.

\subsection{Data Collection}

The following data collection was provided by A clinic's financial accountant and authorized by the owner, the related sales performance data and reports were started from year 2013 to 2016. P clinic and A clinic belongs to the same owner, P clinic is originally a general Obs \& Gyn clinic since 1980 and A clinic started in 2011, since then P clinic was jointed into the same management group of A clinic. With 2 years of strategic management planning by the consultant team, A maternal and child healthcare clinic has expanding into several divisions as stated in Figure 3-Strategy expansion.

\subsection{Unit of Analysis}

In order to analyze the implementation of the adopted balanced scorecard, this study used an organization as the unit of analysis. All observations will be done in A clinic, a maternity and baby care clinic in Luzhou, New Taipei City, Taiwan, R.O.C. Established in 2005, A clinic is an expansion clinic from a 22 years old "P Obs and Gyn clinic" practice. The idea for having re-establishment is to provide the local society with an advanced maternity and baby care service. Table 1 showed the comparison chart of $\mathrm{P}$ and A Obs \& Gyn clinic, they are run by the same owner who is the Obs \& Gyn physician of both P \& A with different running strategy.

From an organizational perspective, A clinic consists of several parts: 1) physical

Table 1. Comparison chart of P and A Obs \& Gyn Clinic.

\begin{tabular}{|c|c|}
\hline P Obs \& Gyn Clinic & A Obs \& Gyn Clinc \\
\hline $\begin{array}{l}\text { General Obs \& Gyn operation } \\
\text { system }\end{array}$ & $\begin{array}{l}\text { Management Strategy: Blue Ocean/7's Mckinsey/Adopted Balanced } \\
\text { Scorecard }\end{array}$ \\
\hline Size of Clinic: a 3 Storeys Shop & 10 storeys with two Basements building \\
\hline Number of employee: 24 & Number of employee: 150 \\
\hline $\begin{array}{l}\text { Sales Revenue staining in } \\
\text { certain level }\end{array}$ & Sales Revenue: growth in steady rate trend \\
\hline N/A & $\begin{array}{l}\text { - Postpartum Confinement Center, } \\
\text { - Neonatal Center/Baby Sitting Center } \\
\text { - Cosmetic \& Plastic Surgery/Weight Control } \\
\text { - Oversea development and consultancy } \\
\text { - Healthcare Supplies/Café } \\
\text { - Chinese Women and Children's Health Development Association } \\
\text { - } \quad \text { Nursing Schools cooperation }\end{array}$ \\
\hline
\end{tabular}


assets, including building and all medical instruments, 2) knowledge asset, including the capability and experience in medical fields, by the doctors and all nurse staff, 3) operations element such as the medical team composed of senior and junior specialized doctors, pharmacies, and nursing, 4) non-medical team, including the administration department that mostly deal with managerial issue such as finance, human resource, quality assurance, risk management and operational procedures and 5) shareholders who provide financial resources as well as guidance for future developments. In dealing with this chaotic situation, the shareholders require all decisions to be retrieved from the current competition scheme. Several concepts have been analyzed clearly to find the opportunity to be a firm guidance, including the blue ocean strategy, SWOT, the 7S McKinsey, and the balanced scorecard.

\subsection{Research Framework}

By using a case study analysis, the study proposed a research framework as seen in Figure 1.

This thesis research will be started according to the research framework step by step from data collections, analysis of results, discussions, conclusions and ending in limitations and contributions. The research framework started from the purpose of strategy formulation with golden spirits of promoting human healthy lifestyle with best quality of medical services in the maternal and children health care industry. Secondary with new insights of a dynamic strategy to create more self-payments instead of the national insurance deteriorating payment. Formulation of the intent purpose is important. Moreover, the environmental risk management also plays an important role in the future success or unsuccessfulness. Therefore, the SWOT analysis before execution to study entirely before the strategic planning. Strengths and opportunities symbolize satisfactory performance where weaknesses and threats signify poor performance that might affect the overall outcome. However, strengths and opportunities will not last forever, while weaknesses and threats may turn positive provided we can solve the threatening solution. The following is the SWOT analysis of A Clinic, which was shown in Table 2.

Combining with our insights from stage one and two, the study will develop a strategic direction. Having considered that the organization has already formulated the strategic map, our study aims to provide a secondary consideration to the existing concept. A complimentary strategic map would be the outcome of this stage. From these two concepts, the study will portray how an organization should perform new sets of competitiveness (drawn from the blue ocean strategy) and the level of capability that the organization already has (referring to the $7 \mathrm{~S}$ analysis). Insights from the blue ocean strategy will be used as input to customer perspective and financial perspective, while insights from the 7S McKinsey will be used for improving internal business process and learning-growth perspective. We believe that this study will be able to provide new insights in 


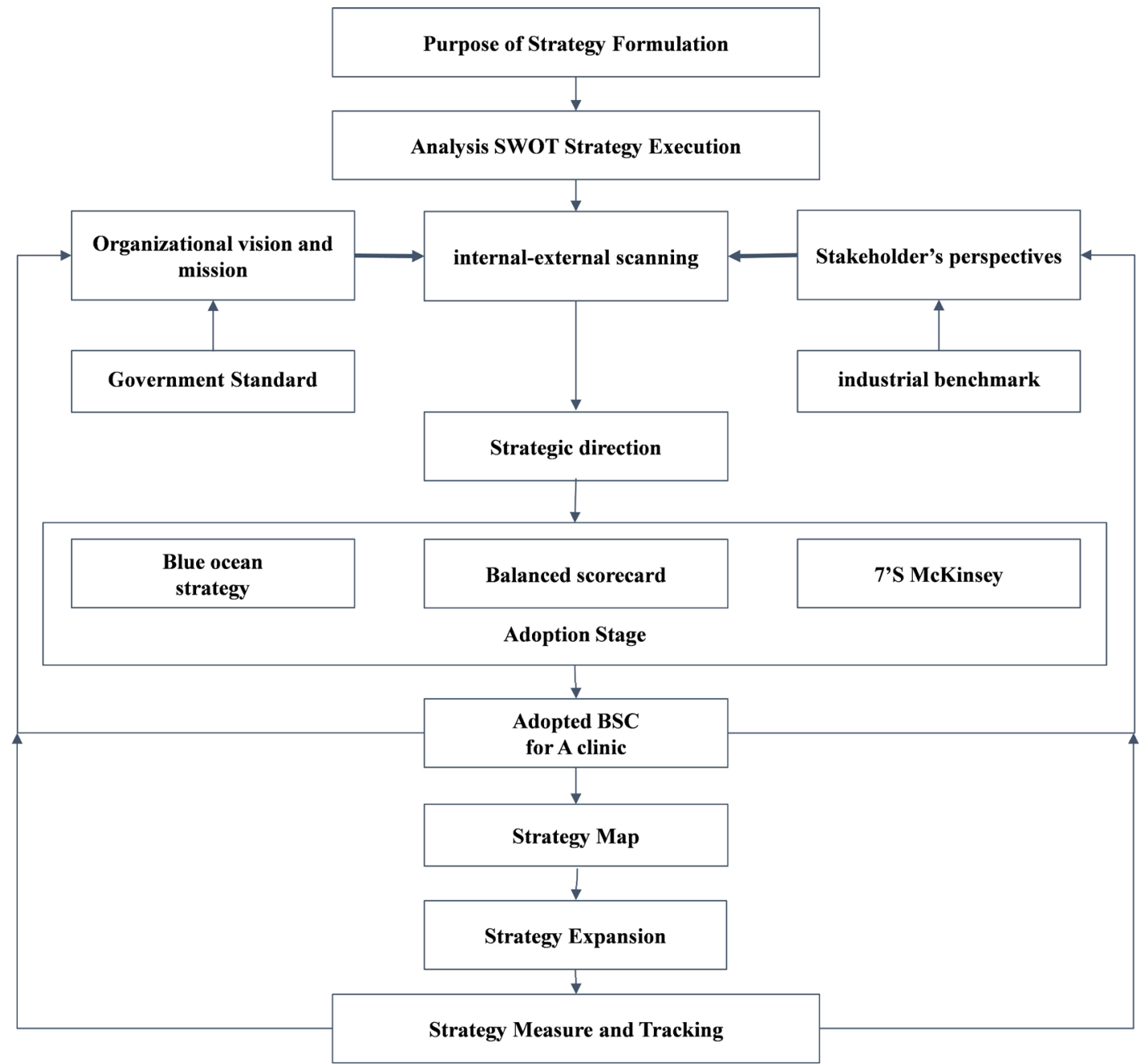

Figure 1. Research framework.

Table 2. SWOT analysis for a clinic.

\section{Strengths}

- Five star medical services

- Prenatal and pediatric specialists

- Neonatal pediatric specialists

- Neonatal cardiologist sepcialists

- Free maternal and Child Healthcare education

- Training program with certification process

- Cooperation in teaching and learning with nursing school

- Group of actuaries, and strategy management

\section{Opportunities}

- Establish good reputation to service more customers

- Copy the same business model to develop branch clinic

- Establish and overseas business in Mainland China in keeping - Negative reviews on internet and media with the two-child policy

- Establish infertility center in Myanmar

\section{Weakness}

- Lack of Obs/Gyn famous doctors

- Shortage of professional nurses with expertise

- Shortage of room vacancies

- Inconvenient location and facilities for public

Threats

- New entrant competitors

- Reduction in local population

- New entrant copy know-how and with abundance of capital investment

- National Health Insurance policy

- Low reimbursement rates

Source: Albert Humphrey; Source: Author conceptualization. 
using the SWOT analysis, the blue ocean strategy, the 7S McKinsey and the adopted balanced scorecard with the final conclusion of value-added strategy framework that might be successful in A's maternal and child healthcare clinic. Furthermore, the findings will be used as inputs to rejuvenate the existing vision and mission. This will provide the best insight that can be used as new knowledge to the stakeholders.

Figure 2 Strategy Map with the fundamental concept of an adopted BSC that composes of financial, customers, internal process, learning and growth 4 perspectives. Table 3 is the sum of value-added that linking to financial, customers, internal process, learning and growth respectively.

\subsection{Shared Value}

Research framework plays an important role in the creation of value added to the further expansion of shared value. The linkages connection from the beginning of SWOT analysis, internal-external scanning, organizational vision and mission, Government policy, stakeholder and health care industry benchmark, each of the solutions contributed a strategic direction to converge Blue Ocean Strategy, Balanced scorecard and 7s Mckinsey that finally formulated adopted Balanced scorecard with new insight to solve the low reimbursement insurance payment system. It's because of their individual contributions to the child and maternal Healthcare services, as a result it makes profitable.

In general, shared value is the contribution to society and economy where a company creates productions that are beneficial to the people, company and the society. The shared value in this thesis contributed from the strategic map is under the development of adopted balanced scorecard, blue ocean strategy and $7 \mathrm{~s}$ Mckinsey theory. In the healthcare industry, it serves as keeping people in a healthy life, staying away from sickness, infectious diseases and maintain the best quality of lifestyle. More advanced medical services to the patients and with high-end technology equipment, this refers to customers perspective. As for financial perspective, a blue ocean strategy with value innovation creates new market-oriented and demands in geographic expansion that increased more self-payments and stabilized financial incomes. Internal process perspective with the external and internal scanning, 7s Mckinsey theory formulated a strong decision making that govern the execution procedure. As for learning and growth perspective, professional staff training, $\mathrm{R}$ and $\mathrm{D}$, nursing school co-operations make a big contribution to human resources. All in all, the above shared value is the sum of contributions from BSC, BOS and 7s Mckinsey theory.

However, new insights of Blue Ocean Strategy and 7's Mckinsey theory take part in different perspective according to their value-added. However, sharing value is the sum of all strategy map undertaking. Blue Ocean strategy in financial and customer perspective enhances and enriches their performance to a higher level of expansion. Furthermore, 7's Mckinsey theory also acts an important role in internal process, learning and growth that contribute more motivations and 
innovations for further expansion. Every perspective implementation plans are guided by the shared value of A clinic that generated from the vision and mission as the organization culture or style of A's maternal \& child healthcare system. The ultimate goal of "balance" in every perspective and individual must be

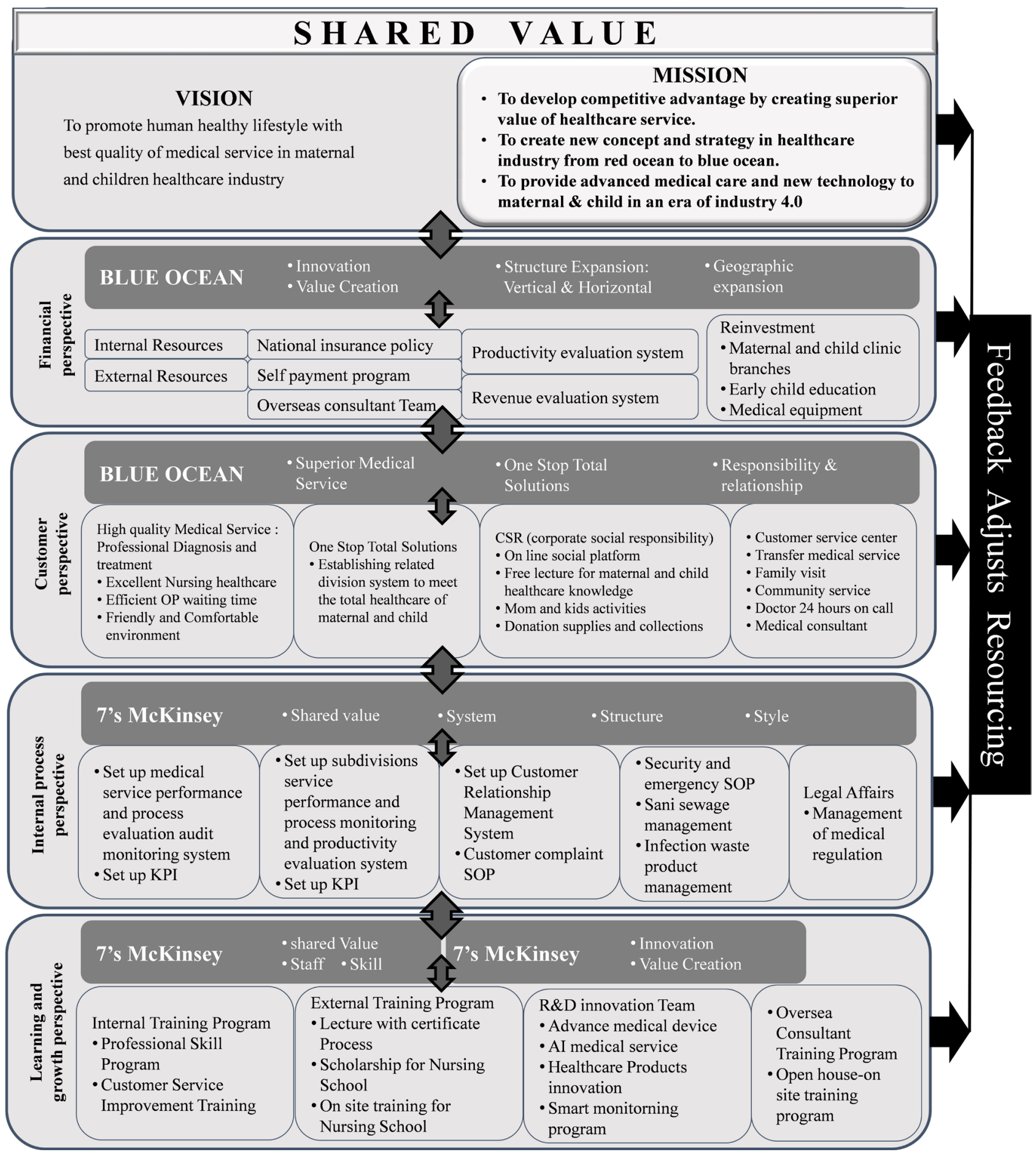

Source: Blue ocean strategy by Kim \& Mauborgne; Source: 7's Mckinsey: Mckinsey consultants: Thomas J. Peters \& Robert H. Waterman Jr. Source: Balanced scorecard by Kaplan and Norton.

Figure 2. Strategy map source: author conceptualization. 
Table 3. Linking of creation value between strategy map and BSC.

\begin{tabular}{ll}
\hline Financial Perspective & Weight control, Cosmetic and Plastic surgery center. \\
\hline Customer Perspective & - 24 hours life secretary for the mother in postpartum confinement rehabilitation center. \\
- & 24 hours professional staff and doctors. \\
- & Postpartum confinement, neonatal center with neonatal pediatric specialist. \\
- & Prenatal fetus early high-resolution echo scanning and neonatal jaundice phototheraphy. \\
- & Vasectomy for family planning service program. \\
- & Free lectures for antenatal exercises and Lamaze childbirth breathing relaxation technique, infant hygeine \\
& program, breast feeding program, and proper food intake for expectant mother and after birth mother. \\
- & Periodic activities set up for the first child born couple family day. \\
- & Community charity works, such as collection of material donations. \\
- & Light meal café corner. \\
- & On line teaching in the social media app (facebook, line, twitter...etc.) and QR code for every division for \\
& expedite the everyday patient visit process.
\end{tabular}

implanted in everyday process. By insisting the share valued should be comprehend led by all of the staff in this organization, the effect of the synergy then will be spread out to every individual, not only the customers, patient, but also the employee, professional staff, and etc. It will definitely reflect on the financial performance which is also a crucial factor to sustain everyone in the organization to be satisfied and a positive circulation will be kept on in the flows of the strategies. Figure 2 shown the strategy map from the process of adoption stage, the map is a guidance for A clinic in executing the adopted BSC system.

The theme of the strategy in patient is to raise up management performance, patient safety and medical quality. In medical performance and quality easily measured by patient mortality and morbidity, patient satisfaction, number of outpatient door, hospitalization and number of surgery. However, patient safety is another main topic to be discussed such as not misgiving of drugs or intravenous injection, medical treatment procedure, surgery and miss diagnosis. The performance of the strategy map executes A Clinic strategy expansion where they develop birth delivery, postpartum confinement center, neonatal center and babysitting center, weight control, cosmetic and plastic surgery café, healthy products, association, nursing school cooperation and oversea consultation.

Figure 3 shows the expansion of the strategy, and it shows very much different from those ordinary obs \& gyn clinic, the vertical expansion can reach out to the "early childhood education" which is under planning by the consultant of A clinic, expected to be started in the year 2018. And from the aspect of horizontal, it is reaching out to the association for women and child healthcare that providing free lectures, training and activities to the community, and also including the Nursing school cooperation that providing the onsite practice environment for the nursing school students after their graduation from their education, furthermore, a scholarship also setup by A clinic for the excellent nurses practice. This action plan is driven by the owner's vision and mission for the social 


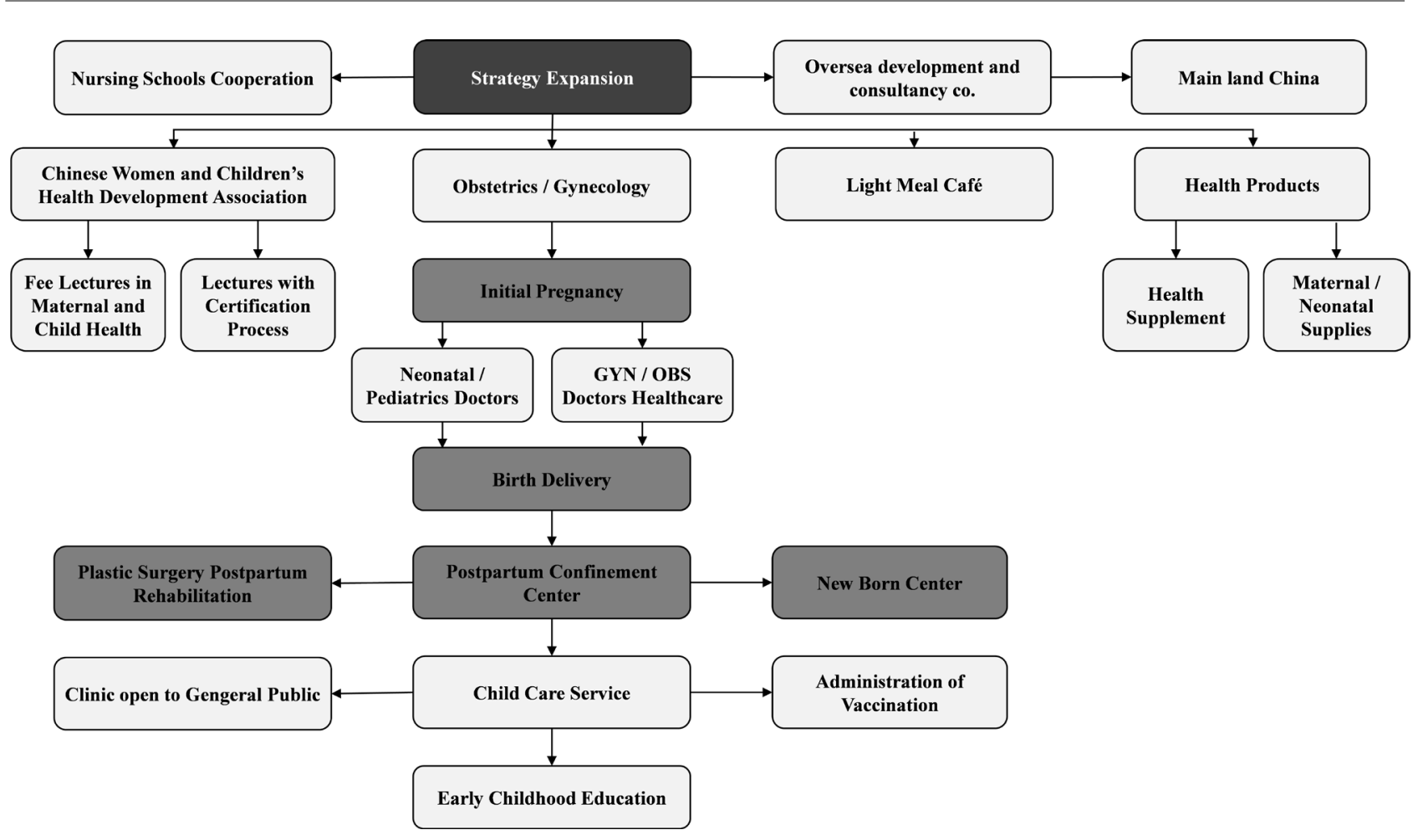

Source: Author conceptualization.

Figure 3. Strategy expansion.

responsibility as he believes that this will generate a positive circulation to the organization eventually. From the aspect of geographic expansion, a consultant team for oversea market was established for assisting the maternal and child healthcare system in mainland China. Since the two-child policy of the China's government policy, the demand in healthcare for maternal and children is booming, the local obs \& gyn clinic is actually in need to transform their operation from the traditional system. A clinic is sending well trained and skilled representatives to assisting their system set up and education program for the organizer and healthcare staff. The overseas team keeps expanding their influencing to other countries in the future.

\section{Results and Analysis}

\subsection{Sales Revenue Performance Analysis}

After 4 years of implementation of the adopted balanced scorecard with new insight from blue ocean and 7's Mckinsey strategies, the positive figure from the financial report speak the truth with overwhelming revenue performance, the result was shown in Table 4.

Figure 4 shows, the revenue of A Clinic with one stop total solution service maternal and child health care system is very much distance if compared with $\mathrm{P}$ Clinic which is just a pure Obstetrics \& Gynecology clinic. The revenue of $\mathrm{P}$ clinic almost maintains in the range of 40 million sales revenue from year 2013 to 2016; however, when the new strategies fall on A Clinic, the sales revenue is 
Table 4. Sale revenue of A clinic's group.

\begin{tabular}{ccccc}
\hline Divisions & $\mathbf{2 0 1 3}$ & $\mathbf{2 0 1 4}$ & $\mathbf{2 0 1 5}$ & $\mathbf{2 0 1 6}$ \\
\hline A's Obs \& Gyn (Ped) & $83,623,841$ & $102,407,164$ & $119,783,229$ & $130,954,016$ \\
Aesthetic \& Plastic Surgery & $12,507,288$ & $20,734,474$ & $23,342,333$ & $23,172,573$ \\
Weight Contol Division & & $1,092,831$ & $1,369,494$ & $1,593,760$ \\
Café & $1,209,788$ & $1,845,679$ & $2,201,641$ & $2,630,307$ \\
Postpartum Confinement Center & $21,686,801$ & $59,534,407$ & $61,490,874$ & $65,597,981$ \\
P Obs \& Gyn Clinic & $40,705,966$ & $40,107,825$ & $39,150,152$ & $40,543,265$ \\
TOTAL & $159,733,684$ & $225,722,380$ & $247,337,723$ & $264,491,902$ \\
Increasing Rate & - & $41.3 \%$ & $9.6 \%$ & $6.9 \%$ \\
\hline
\end{tabular}

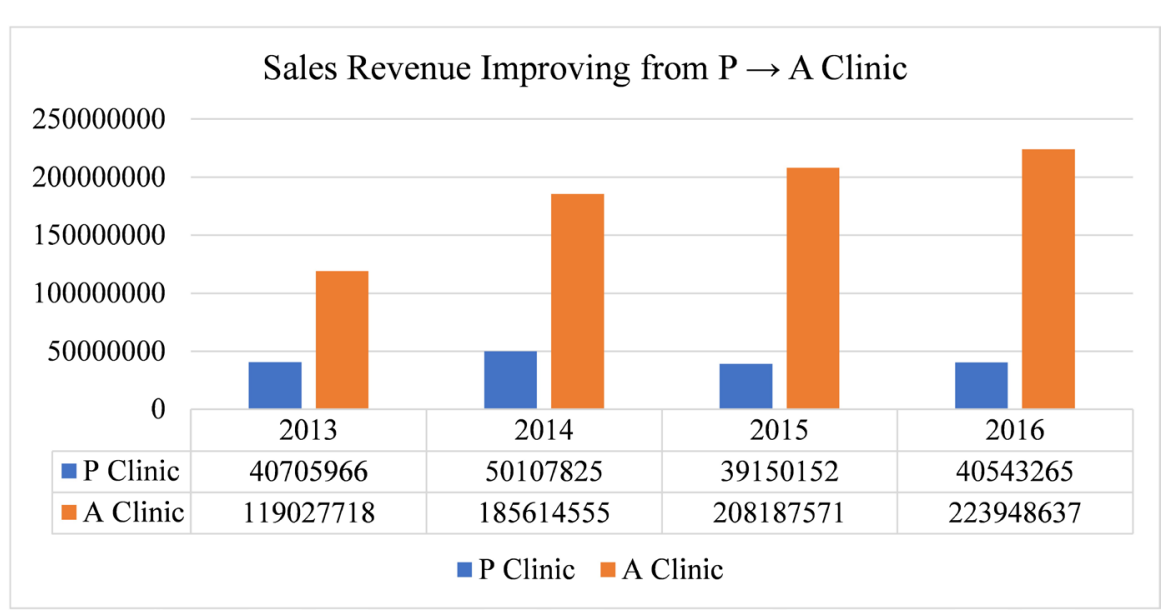

Source: A clinic.

Figure 4. Sales revenue of P \& A clinic.

already at 119 million in the first year (2013) of implementation, and continuously increasing to 224 million in 2016, the rate of increasing from 2013 to 2014 is up to $41.3 \%$ which shows the huge effect from the implementation of BSC, Blue ocean and 7's strategies. The increasing rate from 2014 to 2015 is $9.6 \%$ and 2015 to 2016 is $6.9 \%$. Although the increasing rate is slowing down from 2015 to 2016, this is caused by the limitation of the regional capacity. But in terms of total sales revenue, they are increasing in every year.

Figure 5 shows the "effectiveness" of strategic management, which has brought to the whole group of A clinic, including $\mathrm{P}$ clinic, since they are managed by the same owner. The Annual Sales Revenue comes from each division, including P clinic, shown a substantial upgrading of revenue from 159 million to 264 million.

Annual Revenue Performane from Divisions in Figure 6 which will lead us to observe more deeply into the revenue distribution in each division from 2013 to 2016 which included the P's Obs \& Gyn Clinic. These results of sales performance from A clinic different divisions are interpreting the typical effect of "synergies" which caused by the implementation of the new insight strategies 
Annual Sales Revenue from Clinic's Group Contribution

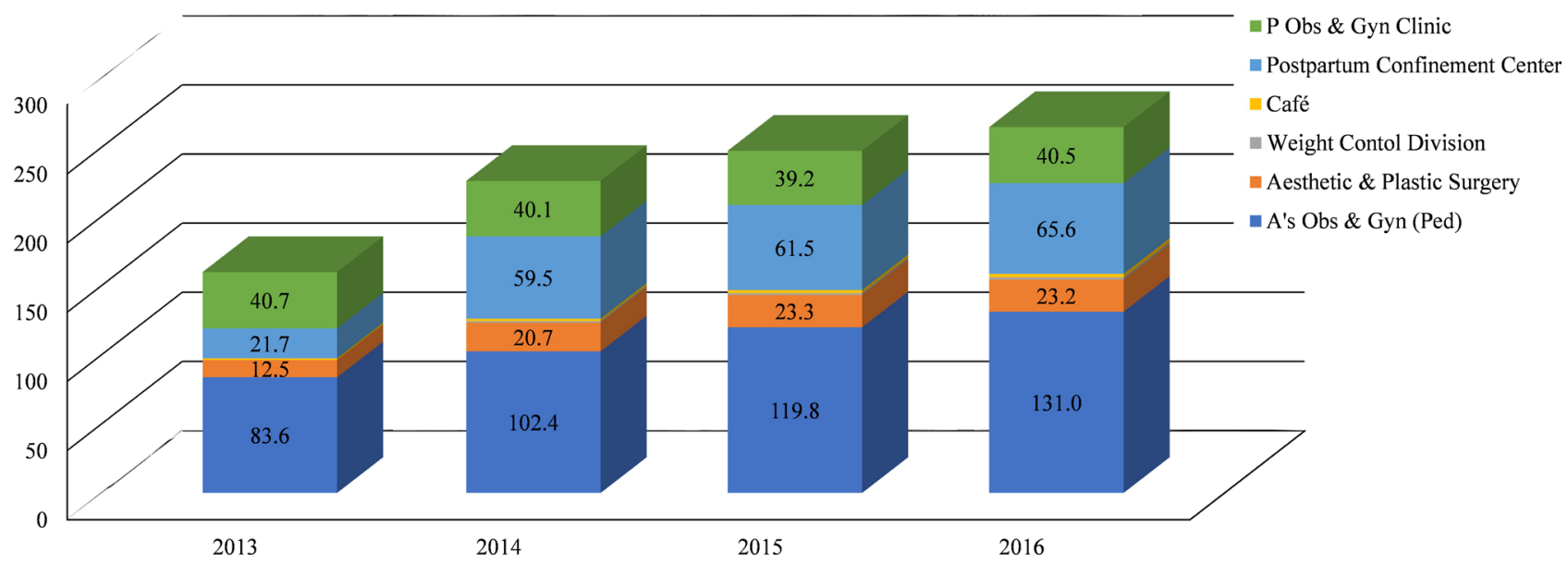

Source: A \& P clinic.

Figure 5. Group annual sales revenue.

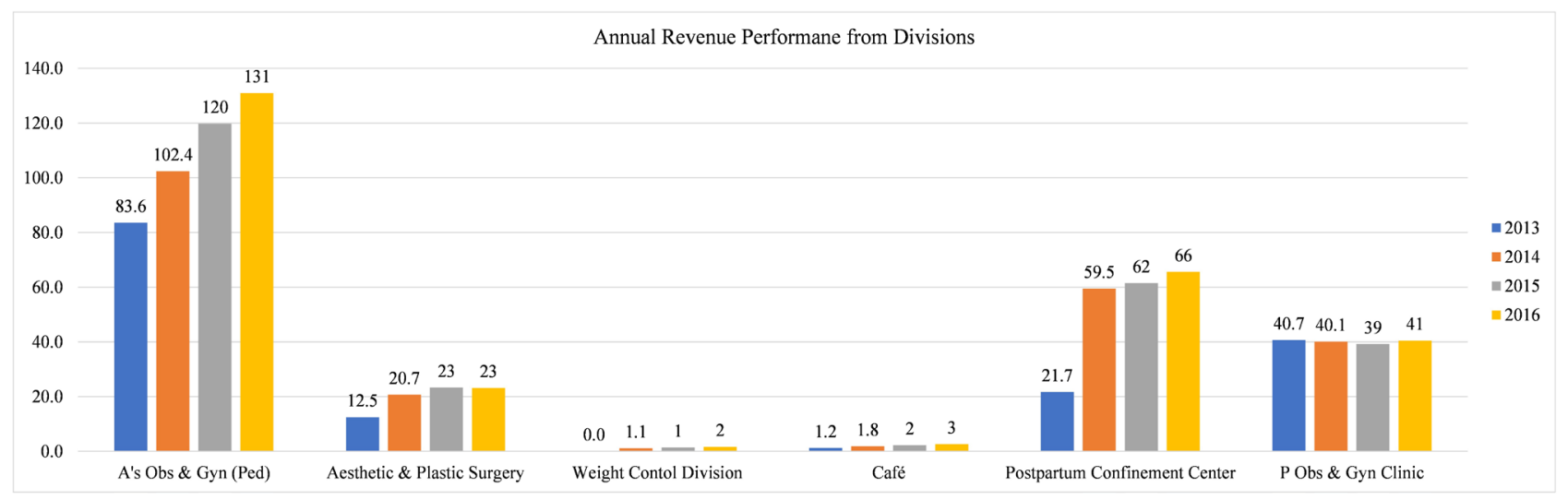

Source: A clinic.

Figure 6. Division's revenue performance.

and value-added framework. In fact, the overall growing sales brought the whole group towards a growing trend and the most important is that they are in interrelated with each other in terms of customers, nurses, doctors, and general staff. The value creation makes the whole group of A clinic booming, and transforming the framework of traditional Obstetrics and Gynecology operating style. P clinic's sales figures have shown the fact that a sole operation unit will actually restrict itself in a highly potential market.

\subsection{Net Profit Margin Performance Analysis}

Net profit is the final gain figure that could enable an organization to enhance their ability to move into a higher professional field and creating a positive shared value circulation.

The chart from Figure 7 is the Net Profit Margin of A clinic, with net profit margin $10.2 \%$ in $2013,14.7 \%$ in $2014,19 \%$ in $2015,21.8 \%$ in 2016 respectively, a huge improvement from $10.2 \%$ (2013) to $21.8 \%$ (2016). This increasing rate in- 
evitably reveals the fact that the total cost of the amortization rate is quite substantially fast which could make the net profit margin in 2016 is $21.8 \%$, immediately reflecting the implementation of the BSC, BOC, 7s Mckinsey are successfully brought to the organization growing in a very positive pace. Net Profit is the most effective management performance indicator, as it always relates to the cost that will be involved in every activity, program, or execution works.

Figure 8 is showing the net profit that gain from each division. The net profit in division Obs \& Gyn of A clinic keep in a steady pace of increasing rate while the sales revenue is also increasing in a steady pace. As stating before, $\mathrm{P}$ clinic is the pioneer Obs \& Gyn in Luzhou district for 30 years, while A clinic establishing, $\mathrm{P}$ clinic also under the same management system with $\mathrm{A}$, which is the main reason that brought her a cost down effect and brought in an upgrade on net profit even though the sales revenue on $\mathrm{P}$ just maintain in a certain level, but the

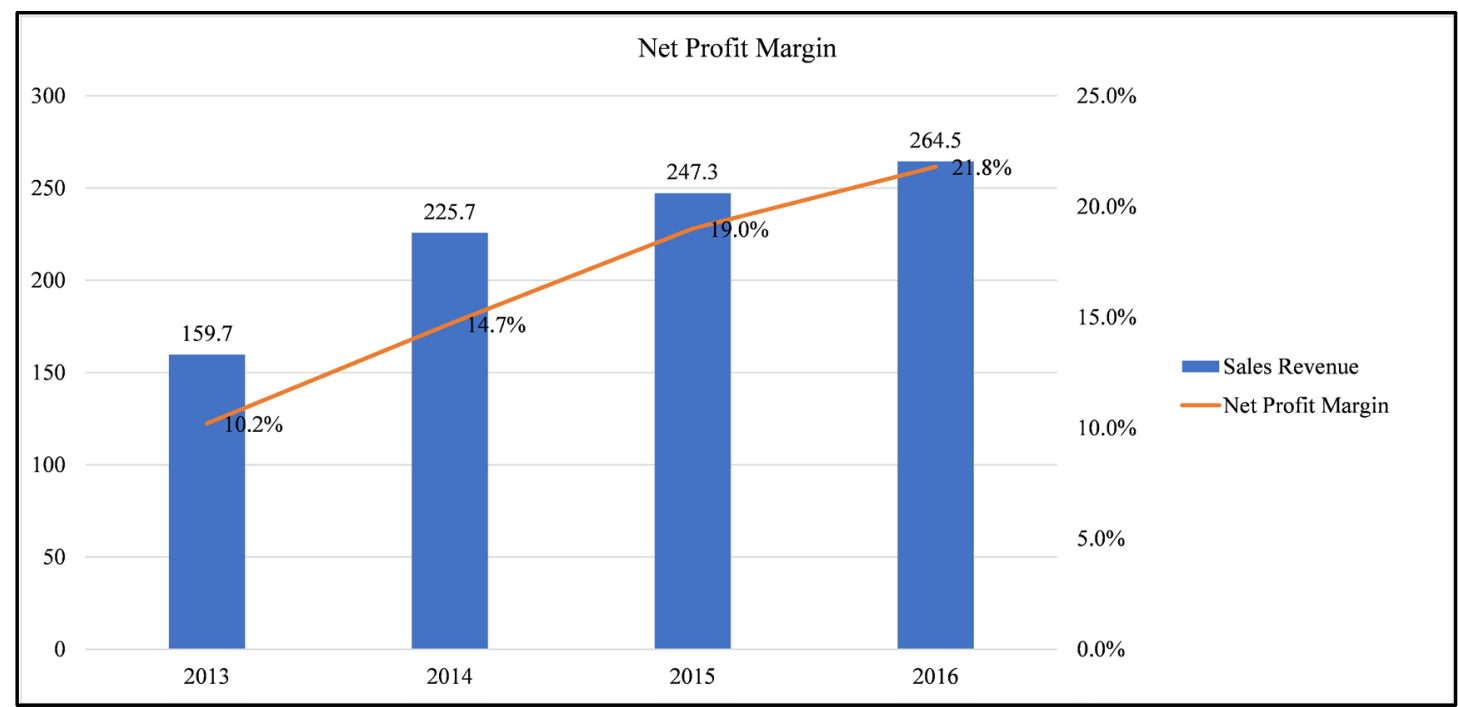

Source: A clinic.

Figure 7. Net profit margin.

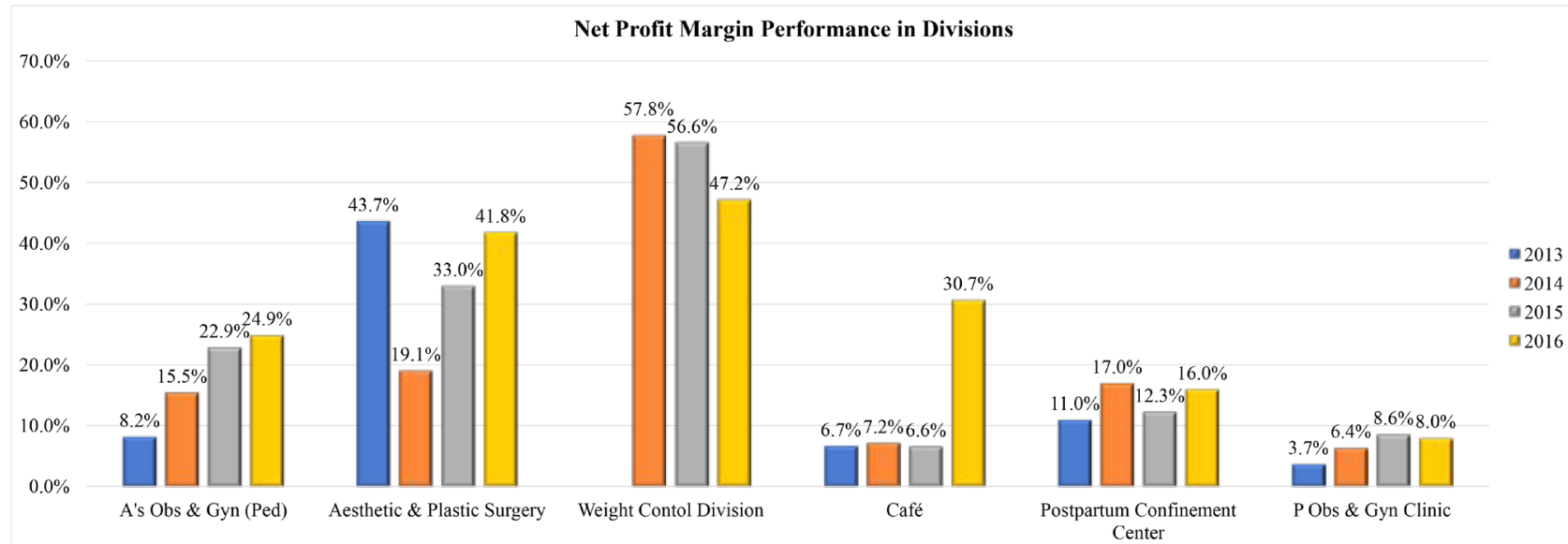

Source: A clinic.

Figure 8. Net profit margin in divisions. 
net profit has quite a preferable outcome every year. The aesthetic center (cosmetic \& plastic surgery) - is a center bringing A clinic much diverse images from other Obs \& Gyn clinic in Taiwan. They are not only providing beauty counsel programs but also plastic surgery for women rebuilding programs after child birth. The division was surprisingly brought $41.8 \%$ of net profit, whereas only $19 \%$ in 2014 which is caused by the investment of medical equipment.

The postpartum confinement center, which is a plus service of Obs \& Gyn, A clinic have put quite an investment effort in this part, pursuing to provide first class care of after birth mother, which complied with Chinese traditional medicine healthcare system. And this division brought at least $16 \%$ of net profit margin in the year of 2016, the reason of decline in year 2013 and 2015 was caused by the high expenditure on employee retaining program (data from A clinic's accounting).

The first-class service of A clinic offering to the after-birth mother is the cozy and comfortable Postpartum confinement center, the occupancy growing rate of $12 \%$ from 2013 to 2014 has shown that the service has given an ignite of the demand. Table 5 showed the occupancy rate of the A clinic's postpartum confinement room:

An almost $98.45 \%$ occupancy rate for the postpartum confinement rooms in 2016 gave an overwhelming demand of new aged mother who also seriously care for the after-birth healthcare and we believe that there is still have huge potential demands in the market.

\subsection{Overseas Consultancy}

The overseas consultancy in Mainland China was started in 2014, that is one of the geographic expansion strategy for A clinic, which bring consultancy performance for the organization with income figures from 0.5 million in 2014 to 10.3 million in 2016 (Table 6) the demand of the women and child healthcare is obviously shown rapidly growth in the mainland China. The consultant team are also assisting the center's nursing staff to have on-site training in A clinic, the cooperation mode will be extending to other countries in the coming years.

\subsection{Solution for $\mathrm{W}$ and $\mathrm{T}$ in SWOT Analysis}

Drawing back to the SWOT scanning at the first stage of strategic planning process, after the implementation of the adopted BSC system, A clinic has found the solutions to cope with their weaknesses and threats. Table 7 and Table 8 show

Table 5. Occupancy rate.

\begin{tabular}{cc}
\hline YEAR & Occupancy Rate \\
\hline 2013 & $84.51 \%$ \\
2014 & $94.53 \%$ \\
2015 & $96.70 \%$ \\
2016 & $98.45 \%$ \\
\hline
\end{tabular}

Source: A clinic. 
Table 6. Overseas consultancy.

\begin{tabular}{|c|c|c|c|c|c|c|c|c|c|}
\hline \multirow[b]{2}{*}{ No. } & \multirow{2}{*}{$\begin{array}{l}\text { Postpartum Confinement } \\
\text { Center in China }\end{array}$} & \multicolumn{4}{|c|}{ Consultancy Contract } & \multicolumn{4}{|c|}{ Period of th Contract } \\
\hline & & $\begin{array}{l}\text { Project Evalution } \\
\quad \& \text { Planning }\end{array}$ & $\begin{array}{l}\text { Constraction } \\
\text { Preparation }\end{array}$ & $\begin{array}{l}\text { Staff Training } \\
\text { Program }\end{array}$ & $\begin{array}{l}\text { Operation } \\
\text { Delegation }\end{array}$ & 2013 & 2014 & 2015 & 2016 \\
\hline 1 & Chengdu Post partum Center & $\mathrm{V}$ & $\mathrm{V}$ & $\mathrm{V}$ & $\mathrm{V}$ & & $\mathrm{V}$ & $\mathrm{V}$ & $\mathrm{V}$ \\
\hline 2 & Chongqing Postpartum & $\mathrm{V}$ & & $\mathrm{V}$ & & & & $\mathrm{V}$ & \\
\hline 3 & Xiamen Postpartum Center & & $\mathrm{V}$ & $\mathrm{V}$ & & & & $\mathrm{V}$ & $\mathrm{V}$ \\
\hline 4 & Zhangzhou Postpartum Center & & & $\mathrm{V}$ & & & & $\mathrm{V}$ & \\
\hline 5 & Quanzhou Postpartum Center & & & $\mathrm{V}$ & & & & $\mathrm{V}$ & $\mathrm{V}$ \\
\hline 6 & Dakian Postpartum Center & $\mathrm{V}$ & & & & & & & $\mathrm{V}$ \\
\hline 7 & Gaungzhou Postpartum Center & & & $\mathrm{V}$ & & & & $\mathrm{V}$ & \\
\hline & & Consultant Fees (R & MB) & & & - & 500,000 & $6,500,000$ & $10,300,000$ \\
\hline
\end{tabular}

Table 7. Solutions to solve A clinic's weaknesses.

\begin{tabular}{ll}
\hline Weakness & Solutions \\
\hline - Lack of OBS/GYN famous doctors & - Famous consultants visiting the clinic twice a month. \\
- Shortage of professional nurses with expertise & $\bullet \quad$ Senior OBS and GYN specialist on duty 24 hours. \\
- Shortage of room vacancies. & $\bullet$ Cooperations with three nursing schools and Chinese Women and Children \\
- Inconvenient location and facilities for public & Development Association. \\
& $\bullet$ Providing scholarships for students and with future work contracts \\
\hline
\end{tabular}

Table 8. Solutions to solve A clinic's threats.

\begin{tabular}{ll}
\hline Threats & Solutions \\
\hline - New entrant competitors. & - First move into the Taiwan Healthcare Industry with \\
- Competition in advanced technology. & comprehensive maternal and child healthcare services. \\
- Negative reviews on internet and media. & Blue ocean Strategy \\
- Reduction in local population. & \\
- New entrants copy know-how and with abundance of capital investment. \\
- National Health Insurance policy \\
- Low reimbursement rates.
\end{tabular}

weakness and threats to A clinic, at the same time we also found the solutions to solve those problems.

\subsection{Summary}

After 4 years of the implementation of adopted Balanced scorecard with new insight strategy framework for the healthcare industry, sales revenue shows a positive financial report with overwhelming revenue performance. In year 2014 increasing rate $41.3 \%, 2015$ increasing $9.6 \%$ and 2016 increasing $6.9 \%$. For the net profit margin performance $10.2 \%$ in $2013,14.7 \%$ in $2014,19 \%$ in 2015 and 21.8\%in 2016 respectively. Furthermore it also shows that a huge improvement 
from $10.2 \%$ (2013) to $21.8 \%$ (2016), it immediately reflecting the implementation of the adopted BSC, BOS and 7s Mckinsey theory are successfully brought to the organization growing in a positive pace. Cosmetic and plastic surgery is another diverse images from OBS and GYN clinic in Taiwan which surprisingly brought $41.8 \%$ of net profits. Postpartum confinement brought at least $16 \%$ of net profit margin in 2016, later due to high expenditures on employee, profit decline in year 2013 and 2015. The occupancy of the postpartum confinement rate increase each year, 2013 (84.51\%), 2014 (94.53\%), 2015 (96.70\%) and 2016 (98.45\%). For overseas consultancy in mainland china was started in 2014, that is one of the geographic expansion strategy for A clinic, which brings consultancy performance for the organization income from 0.5 million in 2014 to 10.3 million in 2016. All in all, the performance of the implementation of adopted Balanced scorecard with new insight strategy framework for the healthcare industry is positive, in conclusion it's a case study, I think it has a hidden potential value for other local clinics to achieve for their low reimbursement payments, perhaps can gain a better profit for themselves.

\section{Discussions}

In this study, by the case study of A clinic, the implemented strategies of BSC, BOS, and 7s Mckinsey have presented a successful model to confront the highly challenging of private healthcare clinic environment with complying the strict national insurance policy by government. The synchronized strategies in this Obs \& Gyn organization bringing the fact that a sole strategy may unsatisfied to cope with the ever-changing environment, instead, a dynamic strategy which could optimize the value creation to customer and patient will keep the clinic organization gaining the competitive advantage.

Healthcare Industry has the obligations, responsibilities and a mission to keep human life in a healthy status by bringing up the preventive medicine and promoting the best quality of medical service. The healthcare industry of Taiwan is under the supervision of National Health Insurance System and all the healthcare organizations should be strictly followed the medical policy. In general, the healthcare industry has obtained very considerably low reimbursement from the National Health Insurance System, even beyond their running cost, which causes the healthcare organization leader to encounter huge dilemma in bringing forth highly supreme quality of medical care. Therefore, new insights and dynamic strategies are the best concept to deal with the current challenge in the healthcare industry.

Low reimbursement from the National Health Insurance that causes heavy financial pressure in medical service. Medical disputes, patient violence and shortage of nursing care, prolong working hours are another big issue and challenge in the healthcare industry. Currently, from red ocean to blue ocean of healthcare industry is a hot topic to be discussed. Therefore, risk management and analysis of SWOT before taking action are essentially important. Adopting 
new insights and concepts from BSC, BOS and 7's Mckinsey to formulate a dynamic strategy for the healthcare industry is an urgent action. From the beginning of the strategic process, SWOT analysis placed in the initial environmental determination. Strengths and opportunities signify good performance, but it doesn't guarantee that it will be good in the future undertaking forever. Witnesses and threats defined not satisfaction in the performance and we need to find out a solution to solve the problem or else it will be much worse than before. Solve the threatening problems and back to positive performance.

The Balanced Scorecard is a useful measurement tool to portray and develop strategy which was proposed by Kaplan and Norton in the early 1990s. It helps many business enterprises from unsuccessfulness back to positive success. However, there are also failures in some of the leaders' misunderstanding the purpose of BSC and errors of implementation, frustration of being in long waiting time to see the result, staff have no idea what the real prospective of BSC is and why the leaders want to implement and perhaps not in the status of cooperative performance. Featured in the book in Search of Excellence, by former Mckinsey consultants Thomas J. Peters and Robert H. Waterman Jr., the model draws 3 hard elements and 4 soft elements interrelated factors that influence an organization's abilities to change. Hundreds of successful and unsuccessful companies were studied and analyzed their successful or poor performance that help them to solve the problems they are facing and a guideline strategy for them to follow from unsatisfaction to success. However, it also contributes suggestions for a good-performance company to become much better than before.

Blue Ocean Strategy is introduced in the early 2000s that conceptualized by Kim and Mauborgne. The concept directs us to create uncontested market space which makes the competition irrelevant with an innovation including products and value-added service. While in the Red Ocean, a company must develop competitiveness to diminish other competitors and become a monopoly player. The trap of BOS should alert back to Red Ocean as the first mover into the market, innovation and differentiation will be the winner, which is a wrong thinking process. All in all, for many business, the fundamental spirits of their original thoughts are not changed unless the environment changes. However, a dynamic strategy is crucial to adopt new insights and concepts for business better performance. Faster, Better and Cheaper written by Dan Nolan emphasizes that all staff should well understand in every detailed step which are important to the company. After A clinic implementation of adopted BSC with new insight and concept, the revenue is steady increasing. As a result, and also maintain $\mathrm{P}$ clinic revenue, it's because both of the clinic belongs to the same owner, therefore, the expanding cost was decrease and profit margin increase.

For more convenient and human resource consideration, such as registration counter, medical records, outpatient department and public health consulting staffs were in the same group. All of them are familiar and well performance in either division, in return their works are dynamic interchangeable. Neonatal 
center who are resident in the clinic as well as mother in the postpartum confinement center, and the other group also in the neonatal division who will be discharged from the clinic after 4 - 5 days. All of the staffs in this division, their work interchangeable. Complied of A and P clinic, accounting, general affairs, public works and warehouse staffs in one group, decrease expenses and simple in management. Forwards and life secretary staff, as well their job also interchangeable.

\section{Risk of Management in Healthcare Industry}

According to the thesis, it is a successful case study in management after implementation of adopted balances scorecard, blue ocean strategy and 7s Mckinsey theory. This study emphasis the importance of a dynamic strategy, new entrants may ask, is it possible to be successful if follow the steps to establish other healthcare industry or business? The answer is uncertain and there is no guarantee that $100 \%$ to be successful. However, some of the criteria should be rendered in mind in order to avoid failure. Firstly, SWOT should be taken into consideration before any execution, whereas internal factor consists of strengths. and weakness, external consists of threats and opportunities. Strength and opportunities symbolize satisfactory performance where weakness and threats signify poor performance that might affect the overall outcome. Strengths and opportunities means good performance in the past and present, it doesn't mean that it will be fine forever. Therefore, more innovation and value creation are endless in practice where threats and weakness need to solve problems and become positive action.

Secondly, formulated a dynamic strategy that suitable for your health care industry. Thirdly, starts business with market-oriented and market demand, make employees satisfaction then customers will be satisfied. Patient safety placed in the first priority then follow by maintaining health away from sickness and infectious diseases. There should not have any error in patient treatment such as misgiven of drugs or surgery, emergency preparedness in massive patients entry the health care unit. Risk management in financial also play an important role in health care industry. Management of medical legislation, public safety such as fire and lift disaster. Prevention of colonies infection, management of contaminants, sewage, and computers services maintenance...etc.

\section{Conclusions}

The mission of healthcare industry is to bring human beings to a healthy life, away from sickness, promotion of healthcare and prevention from infectious disease. Health industry has become more competitive in professional, scientific research, advanced technology and medical services up to 4.0. On the other hand, medico-legal disputes, patient violence and deterioration of health care environment are another big issue to maintain the healthcare industry. Taiwan is under the supervision of National Healthcare Insurance Policy and with low 
reimbursement payment as well as strictly medical regulation. It is supposed to be a red sea industry instead of blue ocean one. Therefore, time is of the essence to create a dynamic strategy for healthcare industry.

One simple method of strategy might not be able to capture the deteriorating health industry; more new insights and concepts from other strategies might enhance this management. All in all, this research is based on the concepts of developing a dynamic strategy with fundamental spirit from adopted balanced scorecard, SWOT analysis of current environment, blue ocean strategy and $7 \mathrm{~s}$ Mckinsey theory to formulate a new dynamic strategy to perform in a local maternal and children healthcare clinic. From the execution of this dynamic strategy implementation, it shows good performance in revenue as well as vertical, horizontal and geographic expansions.

\subsection{Implications}

Most of the researchers are writing $\mathrm{PhD}$ quantitative dissertation with massive volume of data and advanced statistical analysis or qualitative with abundance of literatures review and theory. However, most of the further research or elaboration in detail started from a case study. Therefore, a case study also plays an important role in the scientific field, especially in medicine clinical research. This dissertation research is a case study based on the maternal and children healthcare industry. This local clinic is under the supervision of Taiwan National health care Insurance policy as well as healthcare industry resulted from low reimbursement insurance payment, medico-legal disputes, patient violence and competition among the same industry. The culture of Taiwanese seeking medical centers and famous doctors also shrinks patients sources to local clinics. Therefore, develop a dynamic strategy from new insights and concepts from balanced scorecard, blue ocean strategy and 7'S Mckinsey to apply to the clinic. After the implementation of the dynamic strategy, the clinic shows good performance and revenue. On the other hand, the above 3 strategies still have plenty of room for further business expansion. More research papers to be published and some of the new insights might be helpful for new entrants to deepen further studies.

\subsection{Limitations}

The limitation of this study is obviously in the cases of caparison, since there is always a restriction in data collection from competitors especially for a private clinic, a financial data collection or further step of the management strategies will be considered the most confidential information for this sector. However, as this is a pilot study, and expecting to be considered as a first step for the future further study.

\subsection{Contributions}

This thesis contributed a dynamic strategy in the health care industry. One sim- 
ple strategy might not be able to challenge the current deteriorated environmental changes, particularly under the National Insurance Policy and strictly medical regulations in Taiwan. Therefore, adopt new insights and concepts of the valuable experience from other strategies to flourish the health care industry. After external and internal SWOT analysis of the environment with implications of new insights from BSC, BOS and 7's Mckinsey, currently they create a successful pilot study in a local OBS \& GYN clinic that may give a guideline for the new entrants to practice in the medical field.

\section{Conflicts of Interest}

The authors declare no conflicts of interest regarding the publication of this paper.

\section{References}

[1] Bennett, D., Hung, C.L. and Lauderdale, T.L. (2015) Health Care Competition and Antibiotic Use in Taiwan. The Journal of Industrial Economics, 63, 371-394. https://doi.org/10.1111/joie.12075

[2] Brody, H. (2005) Patient Ethics and Evidence-Based Medicine: The Good Healthcare Citizen. Cambridge Quarterly of Healthcare Ethics, 14, 141-146. https://doi.org/10.1017/S0963180105050176

[3] Ministry of Health and Welfare (2014) Health Promotion Administration. Published file from Ministry of Health and Welfare.

[4] MacKay Memorial Hospital (2013) Annual Management Report. MacKay Memorial Hospital.

[5] Bhagwat, R. and Sharma, M.K. (2007) An Integrated BSC-AHP Approach for Supply Chain Management Evaluation. Measuring Business Excellence, 11, 57-68. https://doi.org/10.1108/13683040710820755

[6] Brewer, P.C. and Speh, T.W. (2000) Using the Balanced Scorecard to Measure Supply Chain Performance. Journal of Business Logistic, 21, 75-93.

[7] Cebeci, U. (2009) Fuzzy AHP-Based Decision Support System for Selecting ERP Systems in Textile Industry by Using Balanced Scorecard. Expert System with Applications, 36, 8900-8909. https://doi.org/10.1016/j.eswa.2008.11.046

[8] Chow, C.W., Haddad, K.M. and Williamson, J.E. (1997) Applying the Balanced Scorecard to Small Companies. Management Accounting, 79, 21-27.

[9] Chow, C.W., Ganulin, D. and Haddad, K. (1998) The Balanced Scorecard: A Potent Tool for Energizing and Focusing Healthcare Organization Management. Journal of Healthcare Management, 43, 263-280. https://doi.org/10.1097/00115514-199805000-00010

[10] Oreski, D. (2012) Strategy Development by Using SWOT-AHP. TEM Journal, 1, 283-291.

[11] Sathidevi, V.K. and Sivadas, M.G. (2013) SWOT Analysis of Medical Education and Training in Government Medical College in Kerala, India. International Journal of Scientific and Research Publications, 3, 1-5.

[12] Silvia, T. and Pramatarov, A. (2016) SWOT Analysis of the Facility Management of Hospitals: The Case of Bulgaria. Academy of Contemporary Research Journal, 5, $1-9$. 
[13] Mutingi, M., Monagent, R. and Mbohwa, C. (2015) Lean Healthcare: Implementation in Southern Africa: A SWOT Analysis. Proceedings of the World Congress on Engineering, Vol. 2, London, UK.

[14] Dyson, R.G. (2004) Strategic Development and SWOT Analysis at the University of Warwick. European Journal of Operational Research, 152, 631-640. https://doi.org/10.1016/S0377-2217(03)00062-6

[15] Kim, W.C. and Mauborgne, R. (2005) Value Innovation: A Leap into the Blue Ocean. Journal of Business Strategy, 25, 22-28. https://doi.org/10.1108/02756660510608521

[16] Aital. P.S. and Kumar, P.M.S. (2015) Black Ocean Strategy-A Probe into a New Type of Strategy Used for Organizational Success. GE International Journal of Management Research, 3, 1-21.

[17] Silviu, M. and Adrian, D.T. (2013) The Green Ocean Innovation model. Global Advanced Research Journal of Management and Business Studies, 2, 536-541.

[18] Chang, S.C. (2010) Bandit Cellphones: A Blue Ocean Strategy. Technology in Society, 32, 219-223. https://doi.org/10.1016/j.techsoc.2010.07.005

[19] Yang, S.C. and Yang, K.J. (2011) An Integrated Model of Value Creation Based on the Defined Kano's Model and the Blue Ocean Strategy. Total Quality Management \& Business, 22, 925-940. https://doi.org/10.1080/14783363.2011.611358

[20] Parvinen, P., Aspara, J., Hietanen, J. and Kajalo, S. (2011) Awareness, Action and Context-Specificity of Blue Ocean Practices in Sales Management. Management Decision, 49, 1218-1234. https://doi.org/10.1108/00251741111163098

[21] Shugan, S.M. (2007) It's the Findings, Stupid, Not the Assumptions. Marketing Science, 26, 449-459. https://doi.org/10.1287/mksc.1070.0293

[22] Sweet, P. (2001) Strategic Value Configuration Logics and the New Economy: A Service Economy Revolution? International Journal of Service Industry Management, 12, 70-83. https://doi.org/10.1108/09564230110382781

[23] Venkatraman, N. (2000) Five Steps to a Dot Com Strategy: How to Foot on the Web. Sloan Management Review, 41, 281-288.

[24] Von Krogh, G. and Cusamano, M. A. (2001) Three Strategies for Managing Fast Growth. Sloan Management Review, 42, 15-21.

[25] Williams, K. (2001) Business as Usual. Economy and Society, 30, 399-411. https://doi.org/10.1080/03085140120089036

[26] Vargo, S.L. and Lusch, R.F. (2004) Evolving to a New Dominant Logic for Marketing. Journal of Marketing, 68, 1-17. https://doi.org/10.1509/jmkg.68.1.1.24036

[27] Roth, S. (2014) Booties, Bounties, Business Models: A Map to the Next Red Ocean. International Journal of Entrepreneurship and Small Business, 22, 439-448. https://doi.org/10.1504/IJESB.2014.064272

[28] Herman, D. (2008) The Limitations of Blue Oceans Strategies and an Unexpected Alternative. Comparative Social Research, 16, 27-42.

[29] Harmon, R. and Demirkan, H. (2011) Redefining Market Opportunities through Technology-Oriented Service Innovation through Blue Ocean Strategy. Management in Energy, Proceedings of PICMET, Portland, OR, 12 September 2011, 1-10.

[30] Bhise, H., Farrell, D., Miller, H., Vanier, A. and Zainulbhai, A. (2000) The Duel for the Doorstep. The McKinsey Quarterly, 2, 33-41.

[31] Vaidyanathan, G. (2005) A Framework for Evaluating Third Party Logistic. Communications of the ACM, 48, 89-94. https://doi.org/10.1145/1039539.1039544 
[32] Sink, H.L. and Langley, C.J. (1997) A Managerial Framework for the Acquisition of Third Party Logistic Services. Journal of Business Logistic, 19, 121-136.

[33] Carr, N. (2003) IT Doesn't Matter. Harvard Business Review, 81, 41-49.

[34] Kimura, T. (1998) The Emergence of Third Party Logistics. NLI Research Institute, Tokyo, Japan.

[35] Lindic, J., Bavdaz, M. and Kovacc, H. (2012) Higher Growth through the Blue Ocean Strategy: Implications for Economic Policy. Research Policy, 41, 928-938. https://doi.org/10.1016/j.respol.2012.02.010

[36] Robertson, P.L. and Langlois, R.N. (1995) Innovation, Networks and Vertical Integration. Research Policy, 24, 543-562. https://doi.org/10.1016/S0048-7333(94)00786-1

[37] Sheehan, N.T. and Vaidyanathan, C. (2009) Using a Value Creation Compass to Discover Blue Oceans. Strategy \& Leadership, 37, 13-20. https://doi.org/10.1108/10878570910941172

[38] Pisano, G. (2006) Profiting from Innovation and the Intellectual Property Revolution. Research Policy, 35, 1122-1130. https://doi.org/10.1016/j.respol.2006.09.008

[39] Steindel, C. and Stiroh, K. (2001) Productivity: What Is It and Why Do We Care about It? Business Economics, 36, 13-34. https://doi.org/10.2139/ssrn.923421

[40] Lieberman, M.B. and Montgomery, D.B. (1988) First-Mover Advantage. Strategic Management Journal, 9, 41-58. https://doi.org/10.1002/smj.4250090706

[41] Wallenburg, C. (2009) Innovation in Logistic Outsoucing Relationships. Journal of Supply Chain Management, 45, 75-93. https://doi.org/10.1111/j.1745-493X.2009.03164.x

[42] Singh, A. (2013) A Study of Role of McKinsey's 7S Framework in Achieving Organizational Excellence. Organizational Development Journal, 31, 39-50.

[43] Bass, B.M. and Avolio, B.J. (1993) Transformational Leadership and Organizational Culture. Public Administration Quarterly, 17, 112-121.

[44] Bhagwat, R. and Sharma, M.K. (2007) Performance Measurement of Supply Chain Management: A Balanced Scorecard Approach. Computers \& Industrial Engineering, 53, 43-62. https://doi.org/10.1016/j.cie.2007.04.001

[45] Inamdar, N. and Kaplan, R.S. (2002) Applying the Balanced Scorecard in Healthcare Provider Organizations/Practitioner's Response. Journal of Healthcare Management, 47, 179-195. https://doi.org/10.1097/00115514-200205000-00008

[46] Gurd, B. and Gao, T. (2007) Lives in the Balance: An Analysis of the Balanced Scorecard in Healthcare Organizations. International Journal of Productivity and Performance, 57, 6-21. https://doi.org/10.1108/17410400810841209

[47] Blumenschein, K., Johannesson, M. and Yokoyama, K. (2001) Hypothetical versus Real Willingness to Pay in the Health Care Sector: Results from a Field Experiment. Value in Health, 4, 79-88. https://doi.org/10.1046/j.1524-4733.2001.40202-36.x

[48] Voelker, K.E., Rakich, J.S. and French, G.R. (2001) The Balanced Scorecard in Healthcare Organizations: A Performance Measurement and Strategic Planning Methodology. Hospital Topics, 79, 13-24. https://doi.org/10.1080/00185860109597908

[49] Grigoroudis, E., Orfanoudaki, E. and Zopounidis, C. (2012) Strategic Performance Measurement in a Healthcare Organization: A Multiple Criteria Approach Based on Balanced Scorecard. Omega, 40, 104-119. https://doi.org/10.1016/j.omega.2011.04.001

[50] Bisbe, J. and Barrubes, J. (2012) The Balanced Scorecard as a Management Tool for 
Assessing and Monitoring Strategy Implementation in Health Care Organizations. Revista Espanola de Cardiologia (English Edition), 65, 919-927. https://doi.org/10.1016/j.rec.2012.05.011

[51] Peng, T.J.A., Pike, S. and Roos, G. (2007) Intellectual Capital and Performance Indicators: Taiwanese Healthcare Sector. Journal of Intellectual Capital, 8, 538-559. https://doi.org/10.1108/14691930710774902

[52] Anna, A. (2015) Strategic Management Tools and Techniques and Organizational Performance: Findings from the Czech Republic. Journal of Competitiveness, 7, 19-36. https://doi.org/10.7441/joc.2015.03.02

[53] Williams, P. and Naumann, E. (2011) Customer Satisfaction and Business Performance: A Firm Level Analysis. Journal of Services Marketing, 25, 20-32. https://doi.org/10.1108/08876041111107032

[54] Yilmaz, C., Alpkan, L. and Ergun, E. (2005) Cultural Determinants of Customer and Learning Oriented Value System and Their Joint Effects on Firm Performance. Journal of Business Research, 58, 1340-1352. https://doi.org/10.1016/j.jbusres.2004.06.002

[55] Venkatraman, N. and Ramanujan, V. (1986) Measurement of Business Performance in Strategy Research: A Comparison Approaches. Academy of Management Review, 11, 801-814. https://doi.org/10.5465/amr.1986.4283976

[56] Chaneta, I. (2015) Strategic Management Process. Journal of Comprehensive Research, 5, 17-26.

[57] Krebs, H.I., Volpe, B.T. and Aisen, M.L. (2000) Increasing Productivity and Quality of Care: Robot-Aided Neuro Rehabilitation. Journal of Rehabilitation, 37, 639-652.

[58] Drucker, P.F. (1999) Knowledge Worker Productivity: The Biggest Challenge. California Management Review, 41, 79-94. https://doi.org/10.2307/41165987

[59] Newhouse, J.P. (1992) Medical Care Costs: How Much Welfare Loss? The Journal of Economic Perspectives, 6, 3-21. https://doi.org/10.1257/jep.6.3.3

[60] Cummings, G.G., MacGregor, T., Davey, M., Lee, H., Wong, C.A., Lo, E., Muise, M. and Stafford, E. (2010) Leadership Styles and Outcome Patterns for the Nursing Workforce and Work Environment: A Systematic Review. International Journal of Nursing Studies, 47, 363-385. https://doi.org/10.1016/j.ijnurstu.2009.08.006

[61] Yin, R.K. (2012) Case study methods. In Cooper, H., et al. (Eds.), APA Handbooks in Psychology. APA Handbook of Research Methods in Psychology, Vol. 2. Research Designs: Quantitative, Qualitative, Neuropsychological, and Biological, American Psychological Association, 141-155. https://doi.org/10.1037/13620-009

[62] Wilson, E.J. and Vlosky, R.P. (1997) Partnering Relationship Activities: Building Theory from Case Study Research. Journal of Business Research, 39, 59-70. https://doi.org/10.1016/S0148-2963(96)00149-X

[63] Stiles, W.B. (2009) Logical Operations in Theory Building Case Studies. Pragmatic Case Studies in Psychotherapy, 5, 245-275. https://doi.org/10.14713/pcsp.v5i3.973

[64] Pentland, B.T. (1999) Building Process Theory with Narrative: From Description to Explanation. Academy of Management Review, 24, 711-724. https://doi.org/10.5465/amr.1999.2553249

[65] Plummer, A.A. (2001) Information Systems Methodology for Building Theory in Health Informatics: The Argument for a Structured Approach to Case Study Research. Proceedings of the 34 th Annual Hawaii International Conference on System Science, Maui, HI, 6 January 2001, 10 p.

[66] Stake, R.E. (1978) The Case Study Method in Social Inquiry. Educational Researcher, 7, 5-8. https://doi.org/10.3102/0013189X007002005 